Micrometric periodic assembly of magnetotactic bacteria and magnetic nanoparticles using audio tapes

M. Godoy, A. J. Moreno, G. A. Jorge, H. J. Ferrari, P. S. Antonel, J. L. Mietta, M. Ruiz, R. M. Negri, M. J. Pettinari, and V. Bekeris

Citation: Journal of Applied Physics 111, 044905 (2012); doi: 10.1063/1.3681380

View online: https://doi.org/10.1063/1.3681380

View Table of Contents: http://aip.scitation.org/toc/jap/111/4

Published by the American Institute of Physics

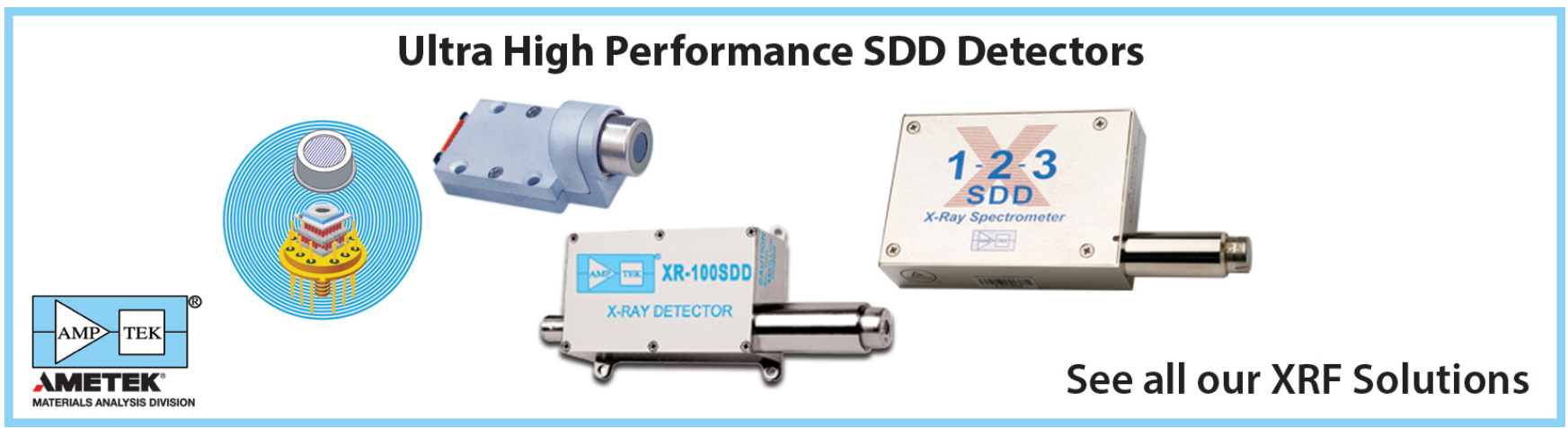




\title{
Micrometric periodic assembly of magnetotactic bacteria and magnetic nanoparticles using audio tapes
}

\author{
M. Godoy, ${ }^{1}$ A. J. Moreno, ${ }^{2}$ G. A. Jorge,${ }^{2,3}$ H. J. Ferrari, ${ }^{2}$ P. S. Antonel, ${ }^{3,4}$ J. L. Mietta, ${ }^{4}$ \\ M. Ruiz, ${ }^{4}$ R. M. Negri, ${ }^{3,4}$ M. J. Pettinari, ${ }^{1,3}$ and V. Bekeris ${ }^{2,3, a)}$ \\ ${ }^{1}$ Laboratorio de Genética y Ecología Microbianas, Departamento de Química Biológica, FCEyN, UBA, \\ Buenos Aires, Argentina \\ ${ }^{2}$ Laboratorio de Bajas Temperaturas, Departamento de Física, FCEyN, UBA, IFIBA, CONICET, Buenos \\ Aires, Argentina \\ ${ }^{3}$ Research Members of National Council of Research and Technology, CONICET, Argentina \\ ${ }^{4}$ Laboratorio de Arreglos Multisensoriales, Departamento de Química Inorgánica, Analítica y Química Física, \\ FCEYN, UBA INQUIMAE, CONICET, Buenos Aires, Argentina
}

(Received 1 November 2011; accepted 22 December 2011; published online 23 February 2012)

\begin{abstract}
We report micrometric periodic assembly of live and dead magnetotactic bacteria, Magnetospirillum magneticum AMB-1, which synthesize chains of magnetic nanoparticles inside their bodies, and of superparamagnetic $\mathrm{Fe}_{3} \mathrm{O}_{4}$ and ferromagnetic $\mathrm{CoFe}_{2} \mathrm{O}_{4}$ nanoparticles in aqueous suspensions using periodically magnetized audio tapes. The distribution of the stray magnetic field at the surface of the tapes was determined analytically and experimentally by magneto-optic imaging. Calculations showed that the magnetic field close to the tape surface was of the order of $100 \mathrm{mT}$, and the magnetic field gradient was larger than $1 \mathrm{~T} \mathrm{~mm}^{-1}$. Drops of aqueous solutions were deposited on the tapes, and bacteria and particles were trapped at locations where magnetic energy is minimized, as observed using conventional optical microscopy. Suspensions of M. magneticum AMB-1 treated with formaldehyde and kanamycin were studied, and patterns of trapped dead bacteria indicated that magnetic forces dominate over self-propelling forces in these experiments, in accordance with calculated values. The behavior of the different types of samples is discussed. (C) 2012 American Institute of Physics. [doi:10.1063/1.3681380]
\end{abstract}

\section{INTRODUCTION}

The manipulation of magnetic nanoparticles into custommade structures ${ }^{1,2}$ is particularly promising for applications in spintronics, novel memory devices, and in biology. ${ }^{3-5} \mathrm{~A}$ variety of techniques have been developed for the handling of magnetic nanowires and superparamagnetic nanoparticles. Examples are magnetic tweezers, ${ }^{6}$ on-chip trapping platforms, ${ }^{7}$ and magnetic garnet films with uniaxial anisotropy. ${ }^{8}$ On the other hand, a variety of microelectromagnets ${ }^{9,10}$ composed of microcoils, ${ }^{11}$ current loops, ${ }^{12}$ and crossed-wire arrays ${ }^{13}$ have been shown to trap and control magnetic nanoparticles. ${ }^{14}$ In these devices, an electric current is injected to generate sufficiently high local magnetic fields and gradients, and Joule heating may be a drawback, ${ }^{10}$ because local thermal energy, $\mathrm{k}_{\mathrm{B}} \mathrm{T}$, competes with the magnetic energy, -m.B, that traps a particle of magnetic moment $\mathbf{m}$ in a magnetic induction field B. Additionally, temperature-induced microfluid convection currents may lead to loss of spatial control by dragging suspended bacteria or particles.

We have explored an alternative approach to assemble live and dead bacteria and two types of magnetic nanoparticles: superparamagnetic magnetite and ferromagnetic cobaltite. The method requires no current bias and uses the micrometric magnetic field patterns generated by recorded

\footnotetext{
${ }^{\text {a) }}$ Author to whom correspondence should be addressed. Electronic mail: vbekeris@df.uba.ar.
}

audio tapes, completely avoiding the inconvenience of Joule heating.

Two main characteristics differentiate a suspension of live magnetotactic bacteria from a suspension of magnetic nanoparticles: (i) bacteria are self propelled, using flagella to swim toward areas containing their preferred oxygen concentration, while aligned with the magnetic field. ${ }^{15}$ In contrast, nanoparticles and dead bacteria passively respond to magnetic forces resulting from magnetic field gradients, and (ii) magnetite chains in bacteria do not cluster due to magnetosome organization that involves a lipid bilayer enclosing the magnetic crystals, ${ }^{16}$ contrary to unfunctionalized magnetic nanoparticles, where dipolar interactions lead to particle clustering.

In this work, we deposited drops of suspensions of live and dead bacteria and of magnetic nanoparticles on clean, previously recorded tapes, as will be described below, and observed the final assembly with optical microscopy. Recorded audio tapes were effective for the assembly of bacteria and of magnetic nano-particles in periodic arrays with wavelengths $\mathrm{L} \geq 25 \mu \mathrm{m}$.

The paper is organized as follows: In Sec. II, we describe the magnetic patterning of audio tapes and the magneto-optic imaging (MOI) technique used to visualize the magnetic stray field in the vicinity of the recorded tapes. In the same section, the growth of magnetotactic bacteria and the synthesis of nano-particles are described. In Sec. III, we present results of the magneto-optical observations of tapes and the analytical calculations of the stray magnetic field generated by the tapes. Magnetic properties of bacteria and of magnetite and cobaltite 
particles are also presented. In the last part of this section, we show the main result of our work: the spatial organization of the different magnetic particles after deposition in solution and solvent evaporation studied by optical microscopy. Conclusions are described in Sec. IV.

\section{EXPERIMENTAL}

\section{A. Periodically magnetized audio tapes}

The physics of tape recording is well understood. ${ }^{17}$ The voltage waveform to be recorded activates a writing head to magnetize the tape as it moves at constant speed in close contact to it. Due to the anisotropy of the magnetic material deposited on the tapes, magnetization is parallel to the tape surface. In this work, we used computer-generated bi-polar square and saw tooth wave functions of different frequencies to record commercial audio tapes. For the highest waveform frequency $f=10^{3} \mathrm{~Hz}$, the magnetization wavelength for the typical tape velocity is $\mathrm{L}=0.048 \mathrm{~mm}$. To determine the magnetization $\pm \mathrm{m}_{0}$ per unit area on each half period, a DC signal (i.e., $\mathrm{L}=\infty$ ) of the same amplitude was recorded for some seconds and the tape magnetic moment was measured with a vibrating sample magnetometer (VSM) at room temperature, resulting in a magnetic moment per unit area $\mathrm{m}_{0}=0.164 \mathrm{~A}$ fixed by the waveform voltage amplitude and by the recording setup.

\section{B. Magneto-optical imaging}

Magneto-optical imaging (MOI) was used for direct observation of the stray magnetic field of tapes. ${ }^{18}$ A polarized light beam illuminates an in-plane magnetized ferrite garnet film (FGF) placed directly on top of the tape. The light passes through the FGF that has a high Verdet constant and is reflected back on a thin $(\sim 120 \mathrm{~nm})$ Au layer deposited on its back face, doubling the Faraday rotation angle, $\theta_{\mathrm{F}}$. By using a pair of polarizers in an optical microscope, it is possible to directly visualize and quantify the field distribution across the tape area. We used a Bi-doped FGF, $\mathrm{Lu}_{3-\mathrm{x}} \mathrm{Bi}_{\mathrm{x}} \mathrm{Fe}_{5-\mathrm{y}} \mathrm{Ga}_{\mathrm{y}} \mathrm{O}_{12}$, with $\mathrm{x} \sim 0.5$ and $\mathrm{y} \sim 0.7$ with in-plane magnetization. ${ }^{19}$ To image each tape, the pair polarizer-analyzer was set slightly out of crossing $\left(\theta_{0}=4^{\circ} \pm 10 \%\right)$, so that perpendicular fields of opposite polarity were distinguished in the MOI image as bright or dark images. The tapes were placed under the indicator film, and a standard Olympus BX60M microscope was used with $20 \times$ magnification, and a Roper Scientific CoolSnap Camera recorded the images.

The analytic calculation of the magnetic field at a plane in close proximity to the tape is presented below, in accordance with the MOI image. The parallel field component is not visualized directly by MOI, but its changes in sign can be related to the appearance of triangular domain walls in the FGF, as observed in previous work. ${ }^{20}$

\section{Growth of bacteria}

Magnetospirillum magneticum AMB-1 was grown at $30^{\circ} \mathrm{C}$ in a flask standard medium $(\mathrm{FSM}){ }^{21}$ Iron was added before autoclaving as ferric citrate $(100 \mu \mathrm{M}$ final concentration), and the $\mathrm{pH}$ of the medium was adjusted to 7.0 with
$\mathrm{NaOH}$. Plates were incubated in an anaerobic jar (Anaerogen OXOID) to generate anaerobic conditions. Liquid cultures were grown without agitation in glass tubes filled to approximately nine-tenths of the volume with FSM medium and plugged with a rubber stopper for at least one week. Culture growth was monitored by measuring the optical density at $600 \mathrm{~nm}$ (OD 600 ) and cell (bacterium) counting in a Neubauer camera. These values were correlated between each other and with the biomass generated. When cultures reached a visible turbidity $\left(\mathrm{OD}_{600} \sim 0.2\right)$, cells were harvested for future analysis.

For magnetic characterization, the cell suspension was repeatedly centrifuged $(8000 \mathrm{rpm}, 6 \mathrm{~min})$ and washed with saline solution at least twice. Pellets of approximately $40 \mathrm{ml}$ were dried at $65^{\circ} \mathrm{C}$ for $48 \mathrm{~h}$ and prepared to be measured in a vibrating sample magnetometer (VSM) (see below).

To test the role of self-propulsion in bacteria assembly, we also studied suspensions of dead bacteria. To avoid cell wall damage, bacteria were killed using formaldehyde or the antibiotic kanamycin as follows: $500 \mu \mathrm{g} / \mathrm{ml}$ kanamycin or $2.5 \%$ formaldehyde were added to bacterial cultures and incubated at room temperature for $2 \mathrm{~h}$.

Figure 1 shows a TEM micrograph of a bacterium showing the ferrite chain and typical dimensions.

\section{Synthesis of $\mathrm{Fe}_{3} \mathrm{O}_{4}$ and $\mathrm{CoFe}_{2} \mathrm{O}_{4}$ nanoparticles}

The $\mathrm{CoFe}_{2} \mathrm{O}_{4}$ nanocrystals were prepared using the chemical co-precipitation method. ${ }^{22}$ A solution mixture of $\mathrm{FeCl}_{3} \cdot 6 \mathrm{H}_{2} \mathrm{O} \quad 0.450 \mathrm{M}$ and $\mathrm{CoCl}_{2} \cdot 6 \mathrm{H}_{2} \mathrm{O} \quad 0.225 \mathrm{M}$ (2:1) in $0.4 \mathrm{M} \mathrm{HCl}$ was prepared and added drop-by-drop to $200 \mathrm{ml}$ of $1.5 \mathrm{M} \mathrm{NaOH}$ previously adjusted to $\mathrm{pH}=12$ at high-speed stirring. The synthesis temperature of $80^{\circ} \mathrm{C}$ was controlled by a water-jacketed reaction vessel using circulating thermostatic bath. The precipitation of $\mathrm{CoFe}_{2} \mathrm{O}_{4}$ nanoparticles occurred immediately, and both high-speed stirring and the desired temperature were maintained during the addition of the cationic mixture. The obtained precipitates were kept vigorously stirred at the desired temperature for $2 \mathrm{~h}$. The synthetic procedure was performed at open atmosphere. Then, $\mathrm{CoFe}_{2} \mathrm{O}_{4}$ nanoparticles were separated from the reaction medium by centrifugation at approximately $12000 \mathrm{~g}$ for $20 \mathrm{~min}$. The resulting precipitates were washed with MilliQ water, and the washing and centrifugation cycles (always at 12 $000 \mathrm{~g}$ ) were repeated until the $\mathrm{pH}$ of the supernatant was nearly 7. Finally, $\mathrm{CoFe}_{2} \mathrm{O}_{4}$ nanoparticles were dried using a vacuum oven at $40^{\circ} \mathrm{C}$ for $24 \mathrm{~h}$. The mean diameter of the

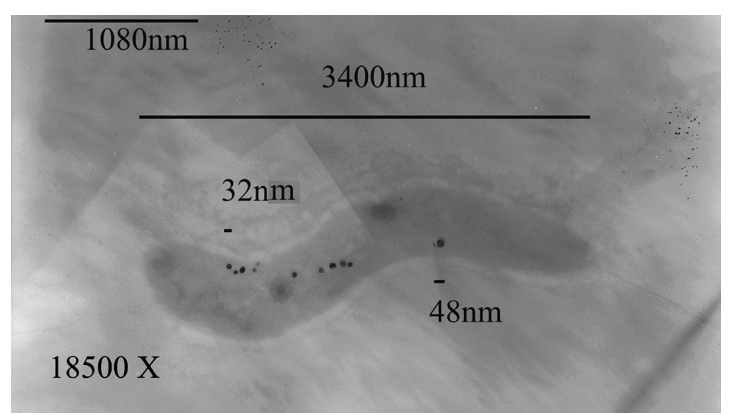

FIG. 1. TEM micrograph of a Magnetospirillum magneticum AMB-1 cell containing a chain of magnetite crystals. 
prepared nanoparticles was $(12 \pm 2) \mathrm{nm}$, as seen by TEM micrographs (not shown). More details concerning characterization of the $\mathrm{CoFe}_{2} \mathrm{O}_{4}$ nanoparticles are described elsewhere. $^{23}$

The chemical co-precipitation method was also used for the synthesis of magnetite nanoparticles: $22.25 \mathrm{ml}$ of a solution's mixture of $\mathrm{FeCl}_{2} \cdot 4 \mathrm{H}_{2} \mathrm{O} \quad 0.679 \mathrm{M}$ and $\mathrm{FeCl}_{3} \cdot 6 \mathrm{H}_{2} \mathrm{O}$ $0.632 \mathrm{M}(2: 1)$ at $0.4 \mathrm{M} \mathrm{HCl}$ was added dropwise to $200 \mathrm{ml}$ of $1.5 \mathrm{M} \mathrm{NaOH}$ solution previously adjusted to $p \mathrm{H}=12$ with high-speed agitation. The synthesis temperature was controlled using a reaction water-jacketed vessel. The precipitation of $\mathrm{Fe}_{3} \mathrm{O}_{4}$ nanoparticles was immediate, and a high stirring speed, as well as the selected temperature $\left(60^{\circ} \mathrm{C}\right)$, was maintained during the addition of the cationic mixture. The precipitates obtained were kept under vigorous stirring at the chosen temperature for $2 \mathrm{~h}$. The synthesis procedure described above was performed under nitrogen atmosphere to prevent oxidation of $\mathrm{Fe}$ (II) to $\mathrm{Fe}$ (III). Then, $\mathrm{Fe}_{3} \mathrm{O}_{4}$ nanoparticles were separated from the reaction medium by ultracentrifugation at approximately $12000 \mathrm{~g}$ for $20 \mathrm{~min}$. The resulting precipitates were washed with MilliQ water, and wash and spin cycles were repeated until the $p \mathrm{H}$ of the supernatant reached the approximate value of 7. TEM micrographs (not shown) indicate an average size of $(14 \pm 2) \mathrm{nm}$ in diameter.

For both $\mathrm{Fe}_{3} \mathrm{O}_{4}$ and $\mathrm{CoFe}_{2} \mathrm{O}_{4}$ nanoparticles, it was confirmed by XRD that 10 cycles of washing and centrifugation also eliminated $\mathrm{NaCl}$, which was present in the reaction medium due to the solutions used in the synthesis. If fewer cycles of washing/centrifugation were performed, the characteristic peaks of $\mathrm{NaCl}$ appeared in the diffractograms. The nanoparticles were dried in vacuum at $40^{\circ} \mathrm{C}$ for $24-48 \mathrm{~h}$.

\section{RESULTS AND DISCUSSION}

\section{A. Magnetic field pattern generated by the recorded audio tapes}

Figure 2(a) shows schematically the normalized inplane magnetization profile for a tape recorded with a square waveform. Figure 2(b) shows an MOI image for $f=100 \mathrm{~Hz}$, including 1.5 spatial periods. The bright and dark lines correspond to positive and negative magnetic field components a)

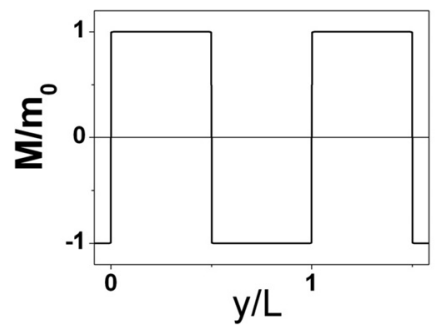

b)

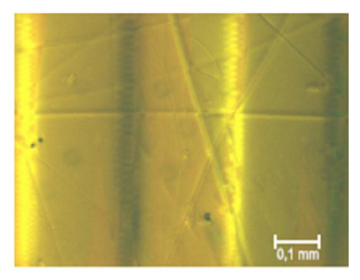

FIG. 2. (Color online) (a) Schematic tape magnetization in units of $m_{0}$ for a square wave form. (b) MOI image of the magnetized tape. Bright (dark) areas represent high positive (negative) perpendicular magnetic field. The distance between two consecutive bright lines is $\sim 500$ microns (frequency $100 \mathrm{~Hz}$ ). Reprinted with permission from H. Ferrari, V. Bekeris, M. Thibeault and T. H. Johansen, J. Magn. Magn. Mater. 313 (2007). Copyright (2007), Elsevier. perpendicular to the tape surface, $B_{z}$, that arise from the $a b$ rupt decrease (from $\mathrm{m}_{0}$ to $-\mathrm{m}_{0}$ ) and increase (from $-\mathrm{m}_{0}$ to $\mathrm{m}_{0}$ ), respectively (note that $\mathrm{m}_{0}$ is the magnetic moment per unit area of the tape, not to be confused with the magnetic moment of particles or bacteria).

In the following paragraphs, we will refer to the coordinate system shown in Fig. 3(a).

We modeled the tape as an infinite strip of width $-\mathrm{w} / 2 \leq x \leq \mathrm{w} / 2$ and thickness $-\mathrm{s} / 2 \leq z \leq \mathrm{s} / 2$, where $\mathrm{s} \ll \mathrm{w}$ and where $\mathrm{L}$ is the wavelength of the in-plane magnetization, $M^{\rightarrow}=M(y) \hat{y}$, and we omitted coordinate $x$, because, as observed in the MOI image, there is a negligible dependence in $x .{ }^{24}$ Furthermore, as will be shown below, the bacteria and particle assembly are also approximately independent of $x$.

We have calculated in detail in previous work the $z$ and $y$ components of the magnetic field for $|z|=\varepsilon \ll \mathrm{L}$ that are given by the following expressions [see Eqs. (13) and (14) in Ref. 24]:

$$
\begin{aligned}
B_{z}= & -\frac{4 \pi}{L} \mu_{0} \sum_{n=0}^{\infty} s g(\varepsilon) \\
& \times\left[n a_{n} \cos \left(\frac{2 \pi n}{L} y\right)-n b_{n} \sin \left(\frac{2 \pi n}{L} y\right)\right], \\
B_{y}= & -\frac{4 \pi}{L} \mu_{0} \sum_{n=0}^{\infty} s g(\varepsilon) \\
& \times\left[n a_{n} \sin \left(\frac{2 \pi n}{L} y\right)+n b_{n} \cos \left(\frac{2 \pi n}{L} y\right)\right],
\end{aligned}
$$

where $a_{n}$ and $b_{n}$ are the magnetization Fourier expansion coefficients, which, in the case of the square wave form, can be represented by the following Fourier series:

$$
M(y)=\sum_{n=0}^{\infty} \frac{4 m_{0}}{\pi(2 n+1)} \sin \left(\frac{2 \pi(2 n+1)}{L} y\right) .
$$

For the sawtooth wave form with a)

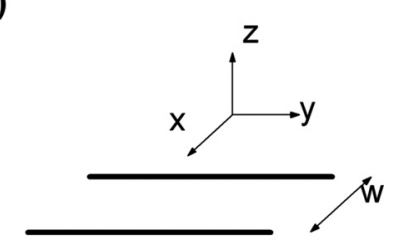

c)

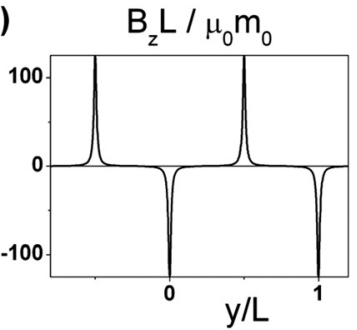

b)

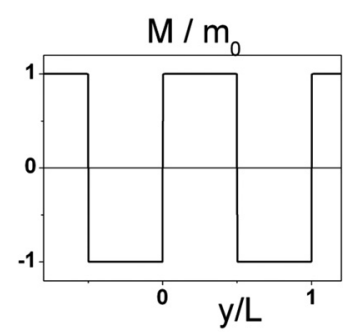

d)

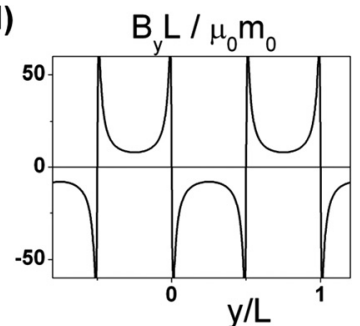

FIG. 3. (a) Strip of width w with in-plane magnetization dependent on coordinate $y$. (b) Sample magnetization in units of $m_{0}$ for square waveform of wavelength L. (c) Calculated perpendicular component $\mathrm{B}_{\mathrm{z}}$ in units of $\mathrm{m}_{0} \mu_{0} \mathrm{~L}^{-1}$. (d) Calculated parallel y component $\mathrm{B}_{\mathrm{y}}$ in units of $\mathrm{m}_{0} \mu_{0} \mathrm{~L}^{-1}$. 

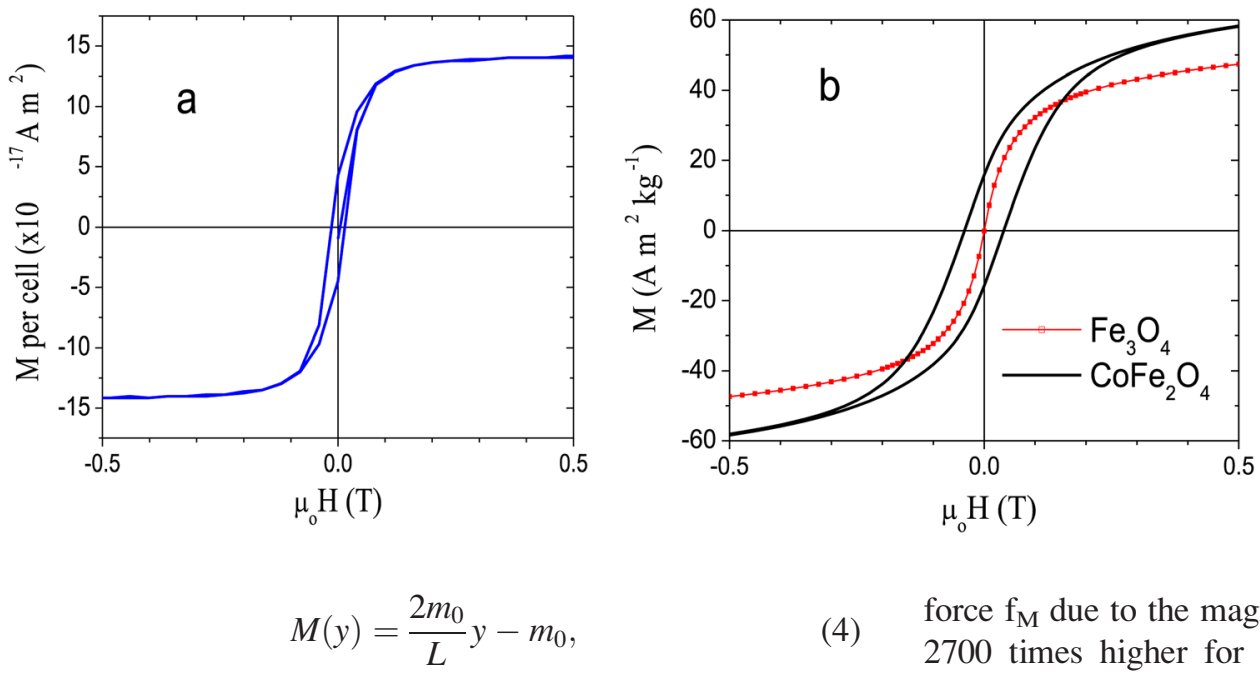

its Fourier expansion is given by Eq. (5),

$$
M(y)=-\sum_{n=1}^{\infty} \frac{2 m_{0}}{\pi n} \sin \left(\frac{2 \pi n}{L} y\right) .
$$

Interestingly, $B_{z}$ is proportional to the gradient of the magnetization [see Eq. (11) in Ref. 24]. The results for $B_{z}$ and $\mathrm{B}_{\mathrm{y}}$ for the square wave function are plotted in Figs. 3(c) and 3(d), respectively, and in Fig. 3(b), we plot again $M(y)$ for comparison. The maximum perpendicular field component for $\mathrm{m}_{0}=0.164 \mathrm{~A}$ and $\mathrm{L}=0.475 \mathrm{~mm}$ is $\mathrm{B}_{\mathrm{z} \operatorname{MAX}}=100 \mu_{0}$ $\pi \mathrm{m}_{0} / \mathrm{L}=100 \mathrm{mT}$. At locations where the $z$ component of the magnetic field is maximum, its $y$ component abruptly changes sign and gradients are maximum. ${ }^{18} \mathrm{~A}$ similar analysis was made for the sawtooth wave form, and $B_{z}$ shows peaks, all of the same sign, with period L (see calculations in Ref. 24).

\section{B. Magnetic characterization of the magnetic particles}

A vibrating sample magnetometer (Lake Shore VSM model 7400) was used to measure magnetic hysteresis loops, $\mathrm{M}(\mathrm{H})$, at room temperature. Results for the bacteria pellets are shown in Fig. 4(a) and for the two types of nanoparticles pellets in Fig. 4(b). For the determination of the magnetic hysteresis curve of bacteria, we prepared pellets of approximately $10 \mathrm{mg}$ of dried bacteria by means of centrifugation cycles and drying in air. The saturation magnetic moment per cell is $\mathrm{m} \sim 1.410^{-16} \mathrm{~A} \mathrm{~m}^{2}$ (about an order of magnitude smaller than the moment of the more commonly studied MS110). ${ }^{10}$ The $\mathrm{Fe}_{3} \mathrm{O}_{4}$ particles with average diameter $(14 \pm 2)$ $\mathrm{nm}$ had $\mathrm{m}=710^{-19} \mathrm{Am}^{2}$ per particle. On the other hand, the magnetic moment per particle of $\mathrm{CoFe}_{2} \mathrm{O}_{4}$ with average diameter $(12 \pm 2) \mathrm{nm}$ was $\mathrm{m}=5.510^{-19} \mathrm{Am}^{2}$ per particle.

However, the particles form clusters due to their dipoledipole interactions, and optical microscopy indicates that the typical cluster volume is similar to the volume of one bacterium, $\sim 0.125 \mu \mathrm{m}^{3}$; then, the magnetic moment for a magnetite cluster is approximately $\mathrm{m}=3.110^{-13} \mathrm{Am}^{2}$ and $\mathrm{m}=3.8$ $10^{-13} \mathrm{Am}^{2}$ for the cobaltite cluster. The magnetic moment of a cluster of particles is then almost 2700 times higher than the magnetic moment of a single bacterium, so that the magnetic force $\mathrm{f}_{\mathrm{M}}$ due to the magnetic field gradient, $\mathbf{f}_{\mathrm{M}}=\nabla \mathbf{m} . \mathbf{B}$ is $\sim$ 2700 times higher for the magnetic clusters than for each bacterium.

\section{Assembly of magnetic particles}

In this subsection, we present the main results of our work. Tapes were tightly fixed on top of a glass slide with the recorded side toward the slide. Drops $(\sim 5 \mu \mathrm{l})$ of the different solutions (with distilled water as a solvent for magnetite and cobaltite particles and growth media for bacteria) were deposited using a micropipette, and surface tension led the drop to fill the space between the glass slide and the tape. The glass slide was observed with a standard Olympus BX60M microscope after solvent evaporation. Highly concentrated solutions (typically $10^{14}$ particles $/ \mathrm{ml}$ ) led to images with an almost homogeneous distribution of particles, where the magnetically trapped particles near the tape surface were covered by the particles in excess. The solutions were then gradually diluted and the procedure of drop deposition repeated until clear images were obtained.

Evidence of particle assembly is presented in Fig. 5 for tapes previously recorded with a $200 \mathrm{~Hz}$ square waveform. The optical micrographs $(50 \times$ magnification $)$ for the $\mathrm{CoFe}_{2} \mathrm{O}_{4}$ and $\mathrm{Fe}_{3} \mathrm{O}_{4}$ nanoparticles and bacteria after solvent evaporation are depicted in Figs. 5(a) to 5(c), showing regular groups $\sim 120 \mu \mathrm{m}$ apart, half the signal wavelength. Large white particles in Fig. 5(c) are residues from bacteria growth medium.

Although the magnetic moment of the whole chain of magnetosomes in one cell of M. magneticum AMB-1 is approximately $1.4 \times 10^{-16} \mathrm{Am},{ }^{2}$ much smaller than the magnetic moment of typical magnetic nanoparticles clusters, bacteria assembly is efficient (see Fig. 5(c)). M. magneticum bacteria possess bipolar flagella and can swim at a speed as high as $100 \mu \mathrm{m} / \mathrm{s}$ parallel or antiparallel to the magnetic field direction, seeking their preferred low oxygen concentration. $^{9,25}$ Bacteria with bipolar flagella ${ }^{26}$ would probably assemble at distances half the wavelength of the recorded signal, at locations where the magnetic energy is minimum, i.e., at $y / \mathrm{L}=\mathrm{n} / 2$, with $\mathrm{n}$ an integer.

To test whether self-propelling forces or magnetic forces dominate, the experiment was repeated using dead bacteria. In this case, $500 \mu \mathrm{g} / \mathrm{ml}$ kanamycin or $2.5 \%$ formaldehyde were added to the control suspension and incubated at room 

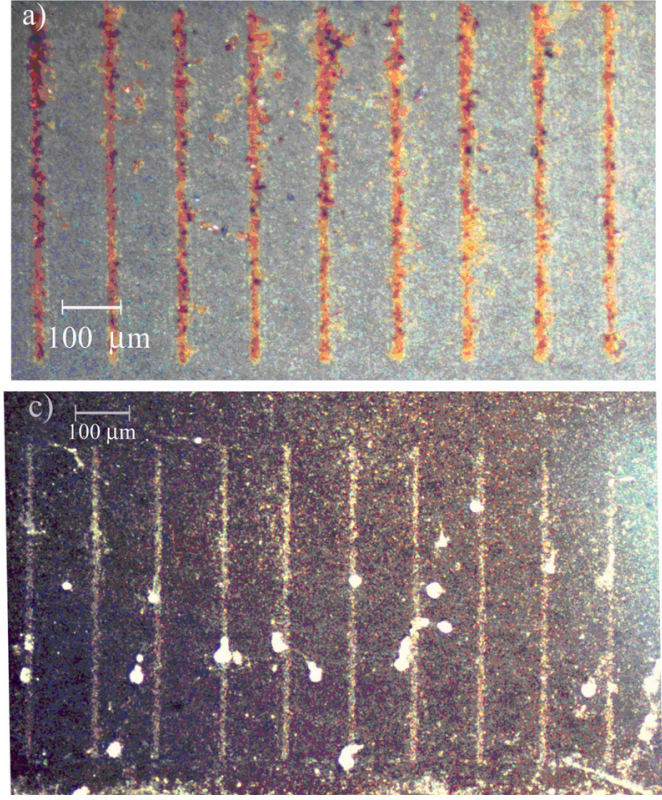

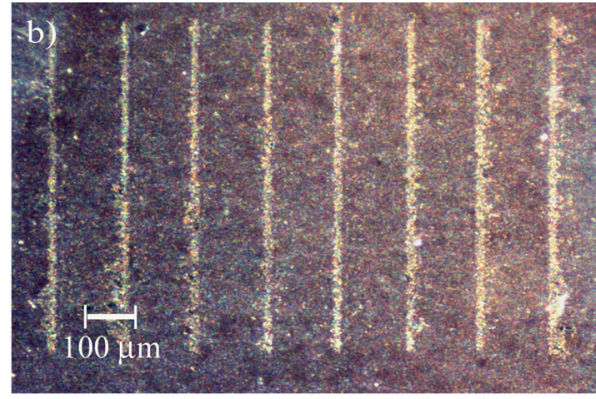

FIG. 5. (Color online) Micrographs' particle assemblies for tapes recorded with a square waveform of $200 \mathrm{~Hz}$. (a) $\mathrm{CoFe}_{2} \mathrm{O}_{4}$ particles, (b) $\mathrm{Fe}_{3} \mathrm{O}_{4}$ particles, and c) M. magneticum AMB-1 after solvent evaporation. The large white particles in (c) are residues from the bacterial growth medium. temperature for $2 \mathrm{~h}$, taking care not to damage the cell walls. ${ }^{27} \mathrm{~A}$ drop of the suspension with live bacteria and a drop of each treated suspension was deposited on the tape using the procedure described above. In this case, the tapes were recorded with sawtooth wave forms of $100 \mathrm{~Hz}$; therefore, the peaks in $B_{z}$ are $476 \mu \mathrm{m}$ apart, pointing always in the same $z$ direction $^{24}$ and minimum magnetic energy occurs at $y / \mathrm{L}=\mathrm{n}$, with $\mathrm{n}$ an integer.

Figure 6 shows micrographs at $60 \mathrm{~s}$ and $1200 \mathrm{~s}$ after drop deposition for the suspension with live bacteria (see panels (a) and (b)), for the suspension with kanamycin (see
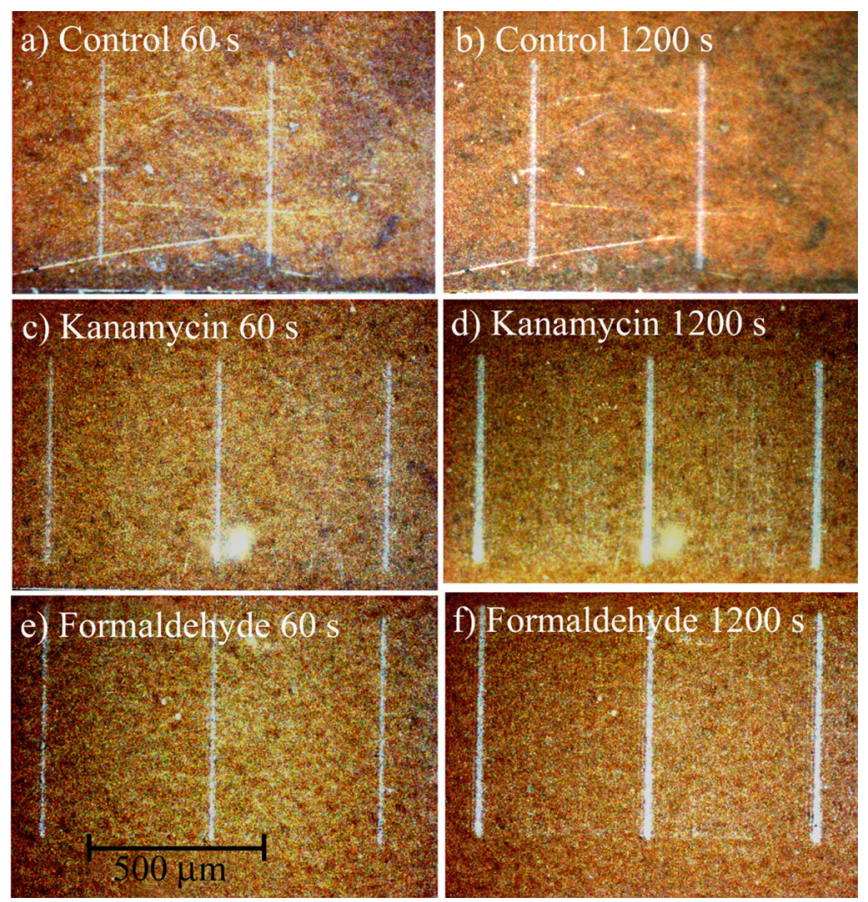

FIG. 6. (Color online) Micrographs at $60 \mathrm{~s}$ and $1200 \mathrm{~s}$ after drop deposition (a) and (b) for the control suspension, (c) and (d) for the suspension with kanamycin, and (e) and (f) for the suspension with formaldehyde. Tapes were recorded with sawtooth waveform of $100 \mathrm{~Hz}$. panels (c) and (d)), and for the suspension with formaldehyde (see panels (e) and (f)), respectively. Spatial organization of dead bacteria (shown in panels (c) to (f)) indicates that self-propulsion is not essential for bacteria assembly in this experiment.

The observation is consistent with magnetic forces dominating over self-propelling forces. The (under)estimated value for the magnetic force per bacterium, $\mathrm{f}_{\mathrm{M}}=\mathrm{m} . \Delta \mathrm{B}_{\mathrm{y}} / \Delta \mathrm{y}$ $\sim 510^{-12} \mathrm{~N}$, is clearly larger than the reported propelling force, $\mathrm{f}_{\mathrm{P}} \sim 10^{-13} \mathrm{~N}$ per bacterium. ${ }^{8}$ It should be pointed out, however, that $f_{M}$ in the vicinity of the final position of bacteria can reach values orders of magnitude stronger than this reported value obtained for an average magnetic field gradient. The increase in the number of trapped bacteria with time is still not clear and may be related to small currents induced by solvent evaporation, gradual decanting of particles, or a combination of both.

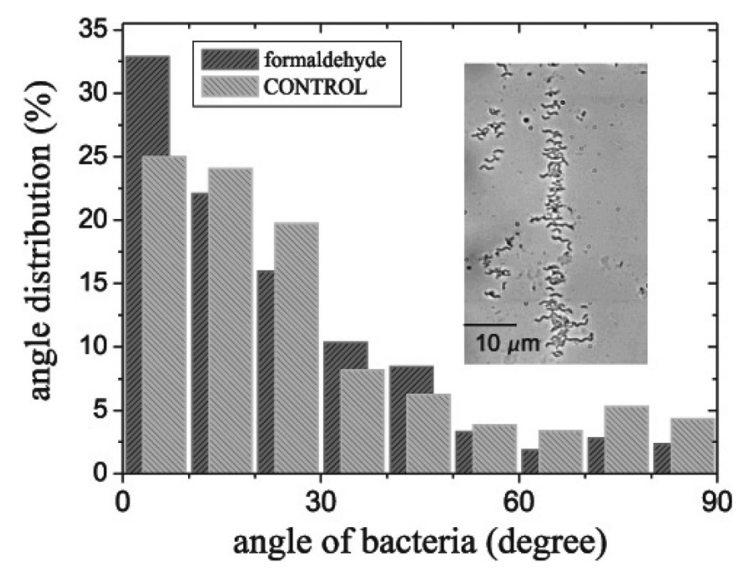

FIG. 7. Percentage of trapped bacteria with angular orientations in respect to $y$ direction. Data for the control sample (light gray) and for the sample treated with formaldehyde (dark gray). The fraction of bacteria that are trapped parallel to the $y$ direction of the tape is larger in the case of dead bacteria. Inset: Micrograph of trapped bacteria, indicating bacteria orientation. 
A close examination of the orientation of bacteria in their trapped positions (see the micrograph in the inset in Fig. 7) reveals that both live and dead bacteria tend to be oriented in the direction of the $y$ component of the magnetic field, as shown in the histogram in Fig. 7. Dead bacteria show a slightly higher tendency to orient parallel to the $y$ direction than bacteria in the control sample, probably due to their passive response to magnetic forces or to their lack of active movement.

\section{CONCLUSIONS}

We have developed a method to assemble magnetotactic bacteria and magnetite or cobaltite nanoparticles in micrometer periodic patterns using commercial audio tapes. The method requires no current application during assembly, avoiding Joule heating that is usually present in microelectromagnet methods. Thermal energy is thus reduced, and long-term positioning is facilitated. The spatial distribution of magnetic fields and magnetic field gradients that determine the assembly can be designed by selecting the audio wave form to be recorded. For square waveforms in the audiofrequency range, local magnetic fields of hundreds of $\mathrm{mT}$ and magnetic field gradients larger than $1 \mathrm{~T} \mathrm{~mm} \mathrm{~m}^{-1}$ are obtained. The efficiency of the method has been demonstrated using $M$. magneticum AMB-1 bacteria with low magnetic moment per bacterium, $\sim 10^{-16} \mathrm{Am}^{2}$, an order of magnitude smaller than the magnetic moment of the commonly studied strain $M$. magnetotacticum MS-1. Suspensions of M. magneticum AMB-1 treated with formaldehyde and kanamycin were examined, and patterns of trapped dead bacteria indicated that magnetic forces dominate over self-propelling forces in these experiments consistently with calculations. The studied magnetite and cobaltite nanoparticles were assembled by the tapes as well, also driven by magnetic forces, and needed shorter time intervals to accommodate in the final spatial distribution than bacteria, probably because their magnetic moment is almost 2700 times larger than the magnetic moment per bacterium. In future work, different waveforms will be recorded to test alternative custom-made magnetic patterns for particle and magnetotactic bacteria assembly.

\section{ACKNOWLEDGMENTS}

M.G. and J.P. thank Arash Komeili for kindly providing us with Magnetospirillum magneticum AMB-1. J.L.M. is the recipient of an undergraduate fellowship of UBA. M.G. and M.R. are Ph.D. students at UBA with a fellowship of the
National Council of Research and Technology (CONICET). Financial support was received from the University of Buenos Aires (UBACyT 2008-2010 X157, UBACyT 2011-2013 661). We also acknowledge support from ANPCYT through PICT 2008 No. 0753.

${ }^{1}$ V. F. Puntes, K. M. Krishnan, and A. P. Alivisatos, Science 291, 2115 (2001).

${ }^{2}$ S. Malynych, H. Robuck, and G. Chumanov, Nano Lett. 1, 647 (2001).

${ }^{3}$ C. T. Black, C. B. Murray, R. L. Sandstrom, and S. Sun, Science 290, 1131 (2000)

${ }^{4}$ S. Sun, C. B. Murray, D. Weller, L. Folks, and A. Moser, Science 287, 1989 (2000)

${ }^{5}$ U. Häfeli, W. Schütt, J. Teller, and M. Zborowski, Scientific and Clinical Applications of Magnetic Carriers (Plenum, New York, 1997).

${ }^{6}$ C. Gosse and V. Croquette, Biophys. J. 82, 3314 (2002).

${ }^{7}$ E. Mirowski, J. Moreland, S. E. Russek, and M. J. Donahue, Appl. Phys. Lett. 84, 1786 (2004).

${ }^{8}$ P. Dhar, Y. Cao, T. Kline, P. Pal, C. Swayne, T. M. Fischer, B. Miller, T. E. Mallouk, A. Sen, and T. H. Johansen, J. Phys. Chem. C 111, 3607 (2007).

${ }^{9}$ A. Krichevsky, M. J. Smith, L. J. Whitman, M. B. Johnson, T. W. Clinton, L. L. Perry, B. M. Applegate, K. O'Connor, and L. N. Csonka, J. Appl. Phys. 101, 14701 (2007).

${ }^{10}$ H. Lee, A. M. Purdon, V. Chu, and R. M. Westervelt, Nano Lett. 4, 995 (2004).

${ }^{11}$ J.-W. Choi, T. M. Liakopoulos, and C. H. Ahn, Biosens. Bioelectron. 16, 409 (2001).

${ }^{12}$ H. Lee, A. M. Purdon, and R. M. Westervelt, IEEE Trans. Magn. 40, 2991 (2004).

${ }^{13}$ H. Lee, A. M. Purdon, and R. M. Westervelt, Appl. Phys. Lett. 85, 1063 (2004); C. S. Lee, H. Lee, and R. M. Westervelt, Appl. Phys. Lett. 79, 3308 (2001).

${ }^{14}$ M. Tanase, D. M. Silevitch, A. Hultgren, L. A. Bauer, P. C. Searson, G. J. Meyer, and D. H. Reich, J. Appl. Phys. 91, 8549 (2002); M. Barbic, J. J. Mock, A. P. Gray, and S. Schultz, Appl. Phys. Lett. 79, 1897 (2001).

${ }^{15}$ R. B. Frankel, D. A. Bazylinski, M. S. Johnson, and B. L. Taylor, Biophys. J. 73, 994 (1997).

${ }^{16}$ Y. A. Gorby, T. J. Beveridge, and R. P. Blakemore, J. Bacteriol. 170, 834 (1988).

${ }^{17}$ R. C. O' Handley, Modern Magnetic Materials, Principles and Applications (Wiley, New York, 2000).

${ }^{18}$ M. R. Koblischka and R. J. Wijngaarden, Supercond. Sci. Technol. 8, 199 (1995); Ch. Jooss, J. Albrecht, H. Kuhn, S. Leonhardt, and H. Kronmüller, Rep. Prog. Phys. 65, 651 (2002).

${ }^{19}$ T. H. Johansen, M. Baziljevich, H. Bratsberg, Y. Galperin, P. E. Lindelof, Y. Shen, and P. Vase, Phys. Rev. B 54, 16264 (1996).

${ }^{20}$ H. Ferrari, V. Bekeris, and T. H. Johansen, Physica B 398, 476 (2007).

${ }^{21}$ U. Heyen and D. Schüler, Appl. Microbiol. Biotechnol. 61, 536 (2003).

${ }^{22}$ Y. I. Kim, D. Kim, and C. S. Lee, Physica B 337, 42 (2003).

${ }^{23}$ S. Antonel, G. Jorge, O. E. Perez, A. Butera, A. G. Leyva, and R. M. Negri, J. Appl. Phys. 110, 043920 (2011).

${ }^{24}$ H. Ferrari, V. Bekeris, M. Thibeault, and T. H. Johansen, J. Magn. Magn. Mater. 313, 98 (2007).

${ }^{25}$ R. B. Frankel and D. A. Bazylinski, ASM News 70, 176 (2004).

${ }^{26}$ G. Harasko, H. Pfützner, and K. Futschik, IEEE Trans. Magn. 31, 938 (1995).

${ }^{27}$ S. Pestka, Methods Enzymol. 30, 261 (1975); M. Misumi and N. Tanaka, Biochem. Biophys. Res. Commun. 92, 647 (1980). 